\title{
Seyhan Nehri'nden Sağlanan Ekosistem Hizmetlerine Yönelik Bakış Açılarının Q Metodoloji Yardımıyla Değerlendirilmesi
}

\author{
Neslihan DOYGUN ${ }^{1 *}$, Hakan DOYGUN ${ }^{2}$ \\ ${ }^{1}$ İzmir Demokrasi Üniversitesi, Meslek Yüksekokulu, Park ve Bahçe Bitkileri Bölümü, 35140, İMİR \\ 2 İzmir Demokrasi Üniversitesi, Mimarlık Fakültesi, Peyzaj Mimarlığı Bölümü, 35140, İZMIR
}

\section{Öz}

Bu çalışmada, Seyhan Nehri’nden sağlanan ekosistem hizmetlerine yönelik bakış açılarının Q metodoloji yardımıyla değerlendirilmesi amaçlanmıştır. Analizler sonucunda konuya yönelik iki farklı bakış açısı belirlenmiş, katılımcıların \%80’i 1 nolu faktörde, \%20'si 2 nolu faktörde yer almıştır. 1 nolu faktörde üzerinde hemfikir olunan başlıca ifade "Seyhan Nehri tarımsal sulama için kaynak sağlar." olmuştur. Bu sonuç, Türkiye ve bölge tarımı için büyük önem taşıyan Çukurova’yı besleyen Seyhan Nehri’nden sağlanan hayatî yararlara yönelik yüksek bir farkındalık söz konusu olduğunu işaret etmektedir. 2 nolu faktörde bir araya gelen katılımcıların üzerinde en çok birleştikleri ifadeler incelendiğinde, en üst sırada "Seyhan Nehri sosyal etkileşim için uygun olmayan ortamlar sunar.” ifadesinin yer aldığı görülmüştür. Genel olarak, Seyhan Nehri’nden sağlanan ekosistem hizmetlerine yönelik olarak 1 nolu faktördeki katılımcıların olumlu, 2 nolu faktördeki katılımcıların ise olumsuz görüş geliştirdiklerini söylemek mümkün bulunmaktadır. Q metodoloji ile yapılacak çalışmaların, insanların bakış açılarını belirlemeye yönelik araştırmalarda, plancıların ve yöneticilerin çalışmalarını daha verimli hale getirmelerinde önemli bir araç olduğu bu çalışma ile ortaya konulmaya çalışılmıştır. Çalışma ile elde edilen verilerin, ülkemizde Q metodoloji ile ilgili yapılacak benzer araştırmalara örnek teşkil etmesi, Seyhan Nehri’ne yönelik gerçekleştirilecek doğa koruma ve kaynak yönetimi faaliyetlerine 1şık tutması beklenmektektedir.

Anahtar Kelimeler: Seyhan Nehri, ekosistem hizmetleri, Q metodoloji, kaynak yönetimi.

\section{Evaluation of Perspectives on Ecosystem Services Provided from Seyhan River by Using Q Methodology}

\begin{abstract}
In this study, it is aimed to evaluate the perspectives on ecosystem services provided from Seyhan River by using $\mathrm{Q}$ methodology. As a result of the analysis, two different perspectives were determined, $80 \%$ of the participants took part in factor 1 and $20 \%$ in factor 2 . The principal expression agreed on in factor 1 is "Seyhan River provides resources for agricultural irrigation.". This result is of great importance for Turkey and the region of Cukurova agricultural feeding suggests that a heightened awareness on the crucial question for the benefits provided by the Seyhan River. When the expressions on which the participants who came together in factor 2 were examined, it was seen that the statement "Seyhan River presents unsuitable environments for social interaction" was found at the top. In general, it is possible to say that the participants in factor 1 developed positive opinions, and participants in factor 2 developed negative views regarding the ecosystem services provided from Seyhan River. This study demonstrated that the studies to be carried out with Q methodology are an important tool in the studies aimed at determining the perspectives of people and in making the work of planners and managers more efficient. It is expected that the data obtained through the study will set an example for the researches will be carried out on $Q$ methodology in our country and shed light on nature conservation and resource management activities to be carried out for the Seyhan River.
\end{abstract}

Keywords: Seyhan River, ecosystem services, Q methodology, source management. 


\section{Giriş}

İnsanlığa fayda sağlayan doğal ekosistemlerle ilişkili birçok koşul ve süreci ifade eden ekosistem hizmetleri kavramı (Van Wilgen vd., 1996), insanların önemli olarak algıladıkları bir dizi mal ve hizmetin sağlanmasını, üretilmesini, korunmasını ve bakımını kapsamaktadır (Chee, 2004). İnsanlar ekosistemlerden sağlanan hizmetlere bağımlı bir şekilde yaşamlarını sürdürmekte iken, giderek artan ihtiyaçların karşılanması eğilimine bağlı olarak özellikle son dönemlerde ekosistemlerde yoğun bir değişim söz konusu olmaktadır (MEA, 2005). İnsan refahı ile doğrudan ilişkili olan ekosistemler üzerine olan bu söz konusu gelişmeler, ekolojik ve sosyal konulara yönelik karar verme süreçlerinde ekosistem hizmetlerini önemli bir araç haline getirmiştir (Gret-Regamey vd., 2017; Cheng vd., 2019; Çiftcioğlu vd., 2019). Bu doğrultuda, ekosistem hizmetlerinin karar destek sistemlerinde bir veri olarak değerlendirilmesi için bu olguların ölçülerle ifade edilebilir hale getirilmesi ihtiyacı ortaya çıkmış (Martinez vd., 2007; Christie vd., 2012), ekosistem hizmetlerinin değerlendirilmesinde ekolojik, ekonomik ve sosyo-kültürel olmak üzere farklı bakış açıları geliştirilmiştir (MEA, 2005; Çiftcioğlu, 2018). Ekolojik değer dayanıklılık ve çeşitlilik gibi indikatörler bakımından incelenirken, ekonomik ve sosyo-kültürel değerler de insanların ekosistem hizmetlerine atfettikleri göreceli değerden yola çıkılarak ölçülmekte, sosyo-kültürel yaklaşım söz konusu değerlendirmeyi para ile ifade etmeyerek ekonomik değerlendirmeden ayrılmaktadır (De Groot vd., 2010; Scholte vd., 2015). Ekosistem hizmetlerinin sosyo-kültürel değeri, insanların birey veya grup olarak ekosistem hizmetlerine verdikleri önem olarak tanımlanmaktadır (Scholte vd., 2015). Ekosistem hizmetlerinin tanımlanmasında yararlı bir yaklaşım olarak öne sürülen sosyo-kültürel değerleme (Oteros-Rozas vd., 2014), insanların ekosistemlerden sağladıkları somut ve soyut faydaları etkin bir şekilde yansıtabilmektedir.

Q metodoloji, bir konu üzerinde kişiler veya gruplar tarafından ileri sürülen düşünceler ve bu konu ile ilgili önceliklendirmeler doğrultusunda ortaya çıkan farklı bakış açılarını incelemek için kullanılan (Stephenson, 1935; Brown, 1993), kişilerin öznel görüşlerini ortaya çıkarması yönü ile nitel (Cross, 2005), bu görüşleri ölçülebilir boyutlarıyla ifade etmesi bakımından da nicel bir yaklaşımdır. Bu yönleri ile Q metodoloji, insanların araştırılan konulara yükledikleri değeri ve önemi ifade etme konusunda sağladığı kolaylıklar nedeniyle giderek yaygınlaşan bir kullanım alanı bulmaya başlamıştır. Hava kirliliği (Sala vd., 2015), iklim değişikliği (Zivojinovic ve Wolfslehner, 2015), alan kullanım değişimi (Swaffield ve Fairweather, 1996), kırsal araştırmalar (Hermans vd., 2011) ve turizm (Jacobsen, 2007) gibi farklı bir çok alanda katılımcıların algılarının ve bakış açılarının belirlenmesinde Q metodoloji yöntem olarak değerlendirilmiş, ayrıca kent parkları (Buchel ve Frantzeskaki, 2015), denizel çevreler (Pike vd., 2015), kıyı alanları (Simpson vd., 2016) ve akarsulardan (Kerr ve Swaffield, 2012) sağlanan ekosistem hizmetlerinin değerlendirilmesinde de etkin bir araç olarak kullanılmıştır.

Bu çalışmada, Seyhan Nehri’nden sağlanan ekosistem hizmetlerine yönelik bakış açılarının Q metodoloji yardımıyla değerlendirilmesi amaçlanmıştır. Çalışma ile elde edilecek verilerin, ülkemizde Q metodoloji ile ilgili yapılacak benzer araştırmalara örnek teşkil etmesi, Seyhan Nehri'ne yönelik gerçekleştirilecek doğa koruma ve kaynak yönetimi faaliyetlerine 1şı tutması beklenmektektedir.

\section{Materyal ve Metot}

Seyhan Nehri’nden sağlanan ekosistem hizmetlerine yönelik bakış açılarının incelendiği bu çalışmada öncelikle Seyhan Nehri ve Q metodoloji hakkında genel bilgilere yer verilmiş, ardından, Q metodoloji süreci bağlamında araştırmanın yöntemi aktarılmıştır.

$560 \mathrm{~km}$ uzunluğa ve $20.000 \mathrm{~km}^{2}$ 'den geniş havza alanına sahip olan Seyhan Nehri Orta Toroslar'dan doğduktan sonra Adana metropol alanını ve Çukurova düzlüklerini katederek Akdeniz'e dökülmekte, üzerinde kurulu bulunan barajlar ve hidroelektrik santralleri ile Türkiye ve bölge için önemli bir enerji, sulama ve içme suyu kaynağı meydana getirmektedir. Adana kentsel gelişimini yönlendirici etkiye de sahip olan Seyhan Nehri, aynı zamanda yöre halkına ticari balıkçılık ve rekreasyonel kullanımlar yönünden önemli bir potansiyel sunmaktadır (Şekil 1). 


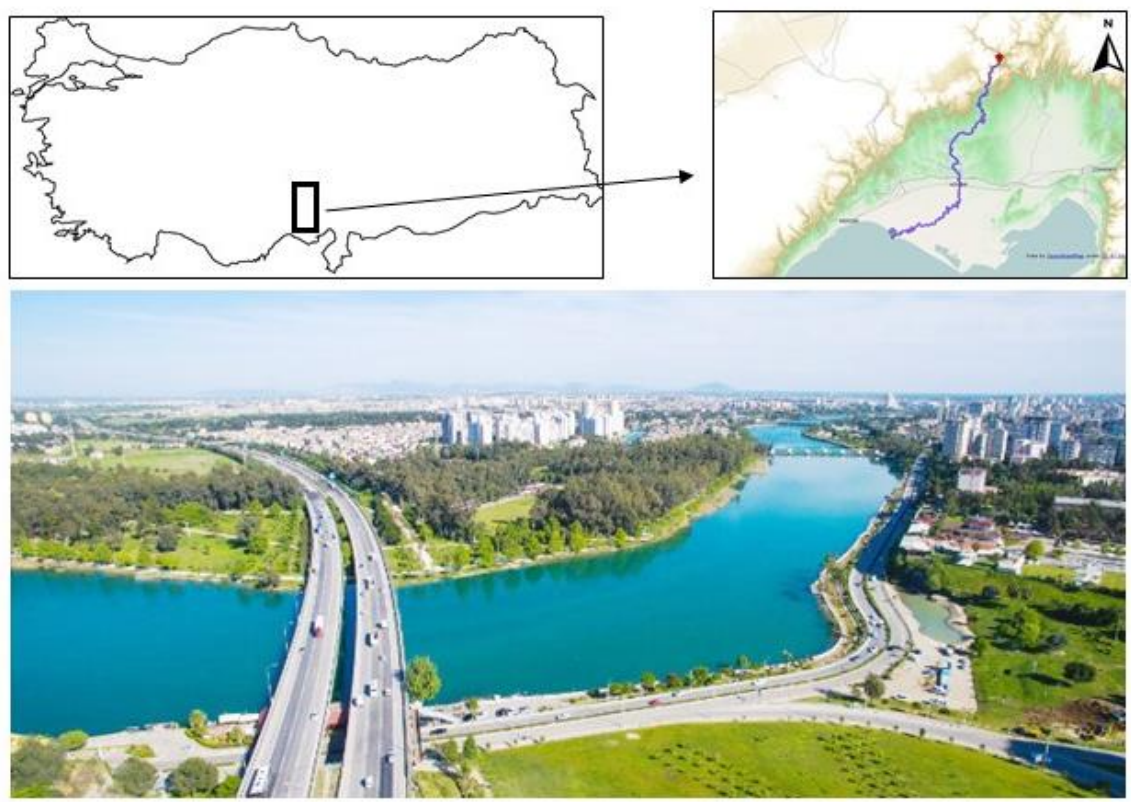

Şekil 1. Seyhan Nehri (Anonim, 2020; Anonim, 2021).

Seyhan Nehri’nden sağlanan ekosistem hizmetlerine yönelik bakış açılarının ortaya konulmasında yararlanılan Q metodoloji, insan öznelliğini ölçmeyi amaçlayan mevcut tekniklere farklı bir yaklaşım getirmek amacıyla Stephenson (1935) tarafından geliştirilmiş olup, araştırılan bir konu üzerinde katılımcılar tarafından ileri sürülen görüşlerin sınıflandırılması işlemine dayanmaktadır (Steelman ve Maguire, 1999; Davies ve Hodge, 2007). Q metodolojide, bir konu hakkında hazırlanan ifadeler katılımcılar tarafından bir dizgi üzerine yerleştirilmekte, ifadelerin dizgi üzerindeki konumlarına dayalı analizin gerçekleştirilmesi ile katılımcıların görüşleri benzer yönleri doğrultusunda ilişkilendirilerek faktörlere ulaşılmakta, elde edilen faktörler araştırılan konuya yönelik bakış açılarını temsil etmektedir (Yıldırım, 2017).

Bir Q metodoloji çalışması genel olarak i) ifadelerin hazırlanması, ii) dizginin tasarlanması, iii) katılımcıların belirlenmesi, $i v$ ) analiz ve değerlendirme aşamalarını içermektedir (Brown, 1993; Watts ve Stenner, 2005; Demir ve Kul, 2011; Karasu ve Peker, 2019). İfadelerin belirlenmesinde konu ile ilgili yapılmış önceki çalışmalar, uzman görüşleri, pilot uygulamalar veya bunların kombinasyonlarından yararlanılmaktadır. Bu süreçte dikkat edilmesi gereken önemli unsurlardan birisi, her ifadenin bir de olumsuzunun, yani karşıt anlamlısının hazırlanması gerektiğidir (Amin, 2000). Çünkü bir ifadenin bazı kişiler tarafından doğru kabul edilmesi ne kadar olağan ise, bunun tersini düşünen kişilerin de bulunabileceğinin göz önünde bulundurulması gerekmektedir. Bir Q metodoloji çalışmasında genel olarak 40-80 arası ifadenin yeterli olacağı belirtilmektedir (Curt, 1994; Stainton Rogers, 1995). Bu çalışmada, Seyhan Nehri'nden sağlanan ekosistem hizmetlerini yansitan ifadelerin oluşturulmasında öncelikle literatürden yararlanılmış (Covich vd., 2004; MEA, 2005), ardından bu ifadeler açıklık, atlanmış içerik, kapsamlılık, ifade bozukluğu, tekrara düşme, ilgili kategoriye uygunluk, gereksiz olup olmama gibi açılardan uzmanlar tarafindan kontrol edilerek 24 ifadeye ulaşılmıştır (Watts ve Stenner, 2005; Karasu ve Peker, 2019) (Şekil 2). Daha sonra her ifadenin bir de karşıt anlamlısı hazırlanmış, böylece toplam 48 ifade elde edilmiştir.

İfadelerin yerleştirileceği dizgi, "Katılmıyorum - Kararsızım - Katılıyorum” aralığında negatif ve pozitif uçlara sahip olan, katılımcıların ifadeler arasında önceliklendirme yapmasını teşvik edecek şekilde ters piramit biçiminde tasarlanmış bir çizelge görünümündedir (Şekil 3). Bu çalışmada, dizginin hazırlanma sürecinde öncelikle ifadeler karışık bir şekilde kutucuklar içerisine yazılmış, sonrasında birer resim formatına dönüştürülerek dizgi üzerinde kolayca yerleştirilebilir hale getirilmiştir. Ardından, ifade sayısı kadar kutucuğa sahip dizgi de benzer şekilde hazırlanarak resim formatına dönüştürülmüş, dizginin ve ifadelerin yer aldığı dosya, katılımın gönüllü olduğunu ve çalışmanın içeriğini belirten bir bilgi notu ile birlikte katılımcılara email ile gönderilmiştir.

Q metodoloji çalışmasında çok sayıda katılımcıya ihtiyaç bulunmamakta, 40-60 arası katılımcının bir konu hakkındaki görüşleri etkin bir şekilde ortaya koyabildiği belirtilmektedir (Stainton Rogers, 1995). Örneğin, Buchel ve Frantzeskaki (2015) kent parklarından sağlanan ekosistem hizmetlerine yönelik değerlendirmeleri 39 katılımcı ile gerçekleştirmişler, Shuib vd. (2016) kent parklarının yararlarına yönelik algıyı 45 katılımcı ile incelemişlerdir. Seyhan Nehri'nden sağlanan ekosistem hizmetlerinin değerlendirilmesini amaçlayan bu çalışma 
da 40 katılımcı ile gerçekleştirilmiştir. Katılımcıların tespitinde, Adana yöresi ve Seyhan Nehri hakkında belirli bilgi ve birikim düzeyine sahip üç kişi öncelikle belirlenmiş, sonrasında bu kişilerden, Seyhan Nehri üzerine değerlendirmeler yapabilecek başka katılımcıları önermeleri istenmiştir (Webler vd., 2009). Katılımcıların en az 10 yıldır Adana'da ikâmet ediyor olmalarına dikkat edilmiş, bakış açıları arasındaki olası farklılaşmaları belirleyebilmek için de yaş ve cinsiyet durumları ayrıca göz önünde bulundurulmuştur. İfadelerin dizgi üzerine yerleştirme işleminin tamamlanmasının ardından, katılımcıların konuya yönelik görüşlerini ifade eden bütün dizgiler PQ Method 2.35 programına aktarılarak faktör analizine tabi tutulmuştur. Söz konusu program, ifadelerin dizgiler üzerindeki konumlarından yola çıkarak, aynı bakış açısı altında birleşen katılımcılardan meydana gelen grupları, yani faktörleri ortaya koymaktadır. Genel olarak faktörler arasında düşük korelasyonlar olması beklenmektedir. Analiz sonucunda her faktör için elde edilen korelasyon değerleri 1'den uzaklaştıkça faktörler arasındaki bakış açılarının birbirlerinden önemli ölçüde ayrıldığı anlaşılmakta, 1'e yaklaştığında ise araştırmaya katılanlar arasında ortaya çıkan grupların birbirleri ile yakın görüşlere sahip oldukları düşünülmektedir.

\begin{tabular}{|c|c|c|c|}
\hline TEDARIKK HIZMETLERİ & DÜZENLEYİCI HIZZMETLER & DESTEKLEYICİ HIZMETLER & KÜLTÜREL HIZMETLER \\
\hline $\begin{array}{l}\text { Seyhan Nehri tarmmsal sulama için } \\
\text { kaynak sağlar. }\end{array}$ & $\begin{array}{l}\text { Seyhan Nehri attkların ortamdan } \\
\text { uzaklaşmasını ve bertarafinı sağlar. }\end{array}$ & $\begin{array}{l}\text { Seyhan Nehri doğanin ve ekosistemin } \\
\text { bütünlüğünü destekler. }\end{array}$ & $\begin{array}{l}\text { Seyhan Nehri dinlenme ve spor } \\
\text { faaliyetleri için ortam sağlar. }\end{array}$ \\
\hline $\begin{array}{l}\text { Seyhan Nehri enerji üretimi için } \\
\text { kaynak sağlar. }\end{array}$ & $\begin{array}{l}\text { Seyhan Nehri doğada su dengesinin } \\
\text { oluşmasina katka sağlar. }\end{array}$ & $\begin{array}{l}\text { Seyhan Nehri yaban hayatı türleri için } \\
\text { yaşama ortamı sağlar. }\end{array}$ & $\begin{array}{l}\text { Seyhan Nehri bölgenin turizm } \\
\text { potansiyelini arturr. }\end{array}$ \\
\hline $\begin{array}{c}\text { Seyhan Nehri nden avlanma yoluyla } \\
\text { besin sağlanır. }\end{array}$ & $\begin{array}{l}\text { Seyhan Nehri bulunduğu bölgede } \\
\text { iklimin iyileşmesine katka sağlar. }\end{array}$ & $\begin{array}{l}\text { Seyhan Nehri biyolojik çeşitliliğinin } \\
\text { korunarak gelişmesi için ortam sağlar. }\end{array}$ & $\begin{array}{l}\text { Seyhan Nehri yerleşim için cazibe } \\
\text { oluşturur. }\end{array}$ \\
\hline \multirow[t]{8}{*}{$\begin{array}{l}\text { Seyhan Nehri içme suyu için kaynak } \\
\text { sağlar. }\end{array}$} & $\begin{array}{l}\text { Seyhan Nehri havadaki kirletici } \\
\text { maddelerin temizlenmesine katka sağlar. }\end{array}$ & & $\begin{array}{c}\text { Seyhan Nehri çevrenin görsel kalitesini } \\
\text { arturr. }\end{array}$ \\
\hline & $\begin{array}{l}\text { Seyhan Nehri doğadaki besin } \\
\text { döngüsüne katka sağlar. }\end{array}$ & & $\begin{array}{c}\text { Seyhan Nehri doğal çevreyi gözlemlemek } \\
\text { ve ögrenmek için ortam sunar. }\end{array}$ \\
\hline & $\begin{array}{c}\text { Seyhan Nehri yağıslarla meydana gelen } \\
\text { yüzey aksşlarını düzenler. }\end{array}$ & & $\begin{array}{l}\text { Seyhan Nehri'ne bakmak gözleri ve ruhu } \\
\text { dinlendirir. }\end{array}$ \\
\hline & & & $\begin{array}{l}\text { Seyhan Nehri yaşanilan çevreye bir } \\
\text { kimlik ve karakter kazandrir. }\end{array}$ \\
\hline & & & $\begin{array}{l}\text { Seyhan Nehri topluma ve çevreye yönelik } \\
\text { aidiyet duygusu gelişmesine katka sağlar. }\end{array}$ \\
\hline & & & $\begin{array}{l}\text { Seyhan Nehri yeni fikirler ve eserler } \\
\text { geliştirilmesi için yaratıc1loğı harekete } \\
\text { geçirir. }\end{array}$ \\
\hline & & & $\begin{array}{l}\text { Seyhan Nehri toplumla iletişim kurmak } \\
\text { için ortam sağlar. }\end{array}$ \\
\hline & & & $\begin{array}{l}\text { Seyhan Nehri doğaya ve çevreye yönelik } \\
\text { farkndalık, sevgi ve koruma bilinci } \\
\text { gelişmesini sağlar. }\end{array}$ \\
\hline
\end{tabular}

Şekil 2. Seyhan Nehri’nden sağlanan ekosistem hizmetlerine yönelik temel ifadeler.

\section{Bulgular}

Katılımcılar tarafından hazırlanan dizgiler analiz edildiğinde, Seyhan Nehri'nden sağlanan ekosistem hizmetlerine yönelik olarak iki farklı faktörün, yani iki bakış açısının ortaya çıktığı görülmüştür. Faktörler arasındaki korelasyon değerleri düşük çıkmış olup, bu durum, konuya yönelik bakış açılarının net bir şekilde birbirinden ayrıldığını göstermektedir (Tablo 1).

Tablo 1. Faktörler arası korelasyon değerleri

\begin{tabular}{lll}
\hline & Faktör 1 & Faktör 2 \\
\hline Faktör 1 & 1.0000 & 0.1252 \\
Faktör 2 & 0.1252 & 1.0000 \\
\hline
\end{tabular}

Araştırmaya katılanların \%80'i (32 kişi) 1 nolu faktörde, \%20’si (8 kişi) ise 2 nolu faktörde yer almıştır. Bu durum, katılımcıların önemli ölçüde belirli bir görüş etrafında toplandığını, yani katılımcı grubun genel bir karakterinin olduğunu göstermektedir. Cinsiyetler bakımından incelendiğinde, katılımcıların 26'sının kadın 14'ünün erkek olduğu ve her iki cinsiyetin de \%80 oranında 1 nolu faktörde yer aldıkları belirlenmiştir. Katılımcılardan 23 kişi 20-40 ve 17 kişi de 41-60 yaş gruplarına dahil olup, yine her iki grubun da \%80’i 1 nolu faktörde toplanmıştır. Katılımcılar için yapılan bu değerlendirmeler Seyhan Nehri’nden sağlanan ekosistem 
hizmetlerine yönelik bakış açıları doğrultusunda irdelendiğinde, çalışmaya katılanların yaş grubu veya cinsiyet gözetmeksizin büyük oranda aynı bakış açısı altında bir araya geldiğini göstermiştir.

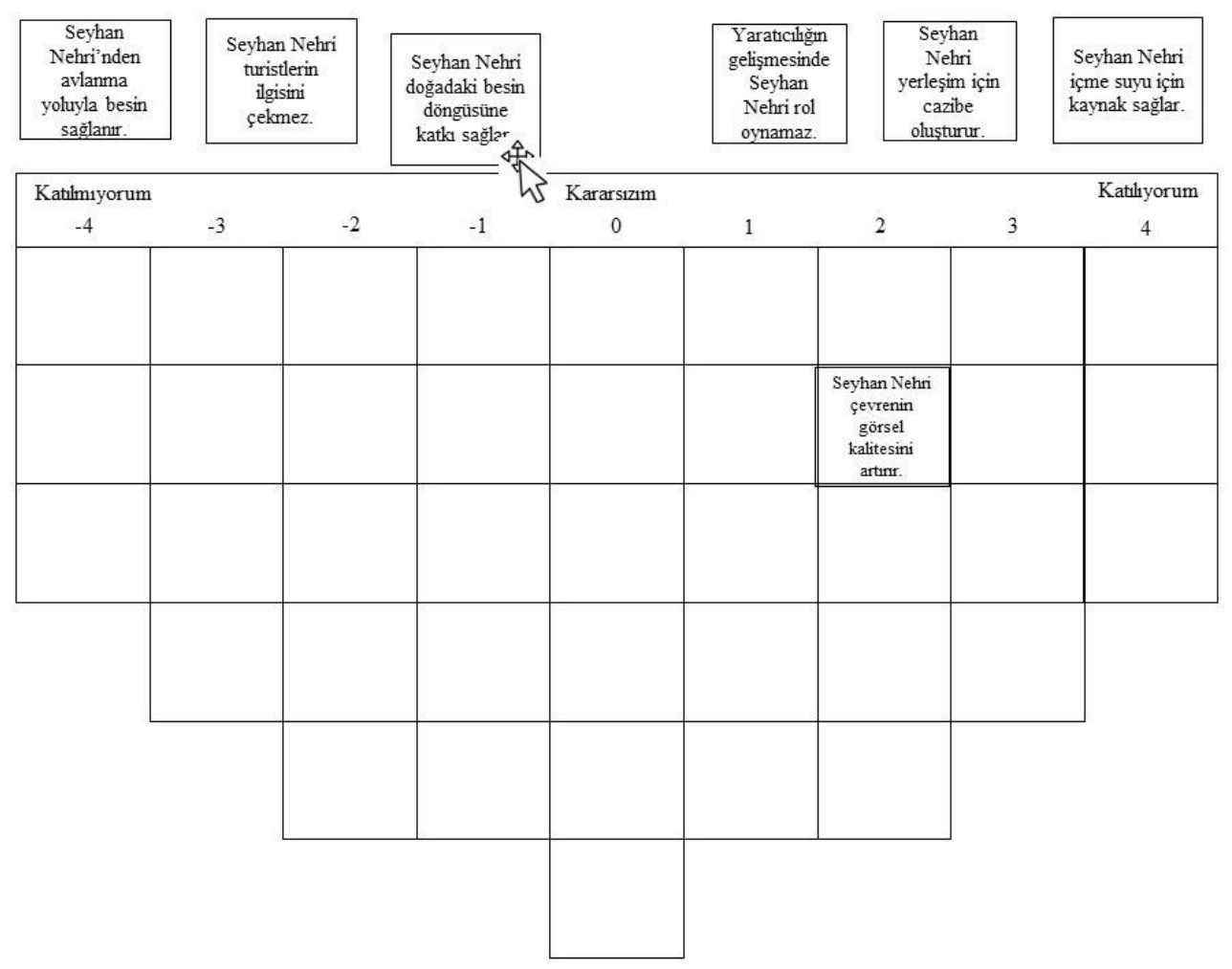

Şekil 3. İfadelerin yerleştirileceği dizgiye ait örnek görünüm.

Katılımcıların hangi ifadeler üzerinde birleştiğini incelemek için analiz sonucunda ifadelerin aldığ $\mathrm{Z}$ değerlerine bakılmaktadır. İfadelerin dizgi üzerindeki konumları "4" kısmında "Katılıyorum” tarafına doğru yaklaştıkça Z değeri 1 ve üzerine çıkmakta, “-4” kısmında "Katılmıyorum” tarafina doğru yaklaştı̆̆ında Z değeri -1 ve altına inmekte, ifadeler "Kararsızım” tarafına doğru yerleştirildiğinde ise Z değeri 0’a (sıfır) yaklaşmaktadır. Bu bağlamda, araştırmaya katılanların çoğunluk sergilediği 1 nolu faktördeki Z değerleri incelendiğinde, "Seyhan Nehri tarımsal sulama için kaynak sağlar." ifadesi üzerinde katılımcıların büyük oranda birleştiğini söylemek mümkün bulunmaktadır. "Seyhan Nehri yerleşim için cazibe oluşturur.” ifadesine katılımcılar Seyhan Nehri'nden sağlanan ekosistem hizmetleri arasında ikinci sırada yer vermişler, "Seyhan Nehri doğanın ve ekosistemin bütünlüğünü destekler." ifadesi ise üçüncü sırada yer almıştır (Tablo 2). 1 nolu faktörde üst sıralarda yer alan ifadeler ekosistem hizmetleri ana başlıklarına göre incelendiğinde, ilk 10 sıradaki ifadelerden 3'er adedinin Tedarik Hizmetleri ve Kültürel Hizmetler altında, 2'şer adedinin de Düzenleyici ve Destekleyici Hizmetler altında yer aldığ 1 görülmüştür. Bu durum, katılımcıların Seyhan Nehri’nden sağlanan ekosistem hizmetlerine yönelik olarak bütüncül bir bakış açısına sahip olduğunu göstermektedir.

2 nolu faktörde bir araya gelen katılımcıların üzerinde hemfikir oldukları ifadeler incelendiğinde, en üst sırada "Seyhan Nehri sosyal etkileşim için uygun olmayan ortamlar sunar." ifadesinin yer aldığı görülmüştür. Sırasıyla "Seyhan Nehri doğanın ve ekosistemin bütünlüğünü destekler." ifadesi ikinci sırada yer almış, bunu "Doğa ve çevre sevgisi Seyhan Nehri olmadan da gelişebilir." ifadesi takip etmiştir. Burada dikkati çeken en önemli unsur, ilk üç sırayı paylaşan ifadelerin ikisinin olumsuz anlam taşımasıdır. 2 Nolu faktörde en yüksek Z değere sahip ilk 10 ifade incelendiğinde de benzer durumla karşılaşılmakta, ilk 10 içerisinde 7 ifadenin olumsuz anlam taşıdığ görülmektedir. Faktörlerde ifadelerin aldığı $\mathrm{Z}$ değerleri göz önüne alınarak yapılan bu değerlendirmeler, faktörlerin temsil ettiği bakış açıları üzerine de fikir geliştirilmesine olanak tanımakta, Seyhan Nehri'nden sağlanan ekosistem hizmetlerine yönelik olarak 1 nolu faktördeki katılımcıların olumlu, 2 nolu faktördeki katılımcıların ise olumsuz görüş sahibi olduklarını söylemek mümkün bulunmaktadır. 
Tablo 2. İfadelere ait $Z$ değerleri ve önem siralaması

\begin{tabular}{|c|c|c|c|c|}
\hline \multirow{2}{*}{ İfade } & \multicolumn{2}{|c|}{ Faktör 1} & \multicolumn{2}{|c|}{ Faktör 2} \\
\hline & $\mathbf{Z}$ & Sira & $\mathbf{Z}$ & Sira \\
\hline Seyhan Nehri tarımsal sulama için kaynak sağlar. & 1.644 & 1 & -1.687 & 47 \\
\hline Seyhan Nehri yerleşim için cazibe oluşturur. & 1.411 & 2 & 0.609 & 14 \\
\hline Seyhan Nehri doğanın ve ekosistemin bütünlüğünü destekler. & 1.337 & 3 & 1.782 & 2 \\
\hline Seyhan Nehri enerji üretimi için kaynak sağlar. & 1.284 & 4 & 0.923 & 13 \\
\hline Seyhan Nehri yaşanılan çevreye bir kimlik ve karakter kazandırır. & 1.275 & 5 & 0.925 & 12 \\
\hline Seyhan Nehri içme suyu için kaynak sağlar. & 1.272 & 6 & -1.545 & 46 \\
\hline Seyhan Nehri çevrenin görsel kalitesini artırır. & 1.244 & 7 & 0.475 & 16 \\
\hline Seyhan Nehri doğada su dengesinin oluşmasına katkı sağlar. & 1.201 & 8 & 0.487 & 31 \\
\hline Seyhan Nehri bulunduğu bölgenin ikliminin iyileşmesine katkı sağlar. & 1.184 & 9 & 0.628 & 35 \\
\hline Seyhan Nehri biyolojik çeşitliliğinin korunarak gelişmesi için ortam sağlar. & 1.172 & 10 & 0.052 & 27 \\
\hline Seyhan Nehri doğadaki besin döngüsüne katkı sağlar. & 1.033 & 11 & 0.525 & 34 \\
\hline Seyhan Nehri yağış ve taşkınlarla meydana gelen yüzey akışlarını düzenler. & 1.024 & 12 & 0.031 & 22 \\
\hline Seyhan Nehri dinlenme ve spor faaliyetleri için ortam sağlar. & 0.997 & 13 & 1.266 & 6 \\
\hline Seyhan Nehri yaban hayatı türleri için yaşama ortamı sağlar. & 0.913 & 14 & 1.025 & 40 \\
\hline Seyhan Nehri'ne bakmak gözleri ve ruhu dinlendirir. & 0.802 & 15 & 0.418 & 19 \\
\hline Seyhan Nehri bölgenin turizm potansiyelini artırır. & 0.639 & 16 & 0.048 & 21 \\
\hline $\begin{array}{l}\text { Seyhan Nehri doğaya ve çevreye yönelik farkındalık, sevgi ve koruma bilinci } \\
\text { gelişmesini sağlar. }\end{array}$ & 0.612 & 17 & 0.383 & 29 \\
\hline Seyhan Nehri havadaki kirletici maddelerin temizlenmesine katkı sağlar. & 0.491 & 18 & 0.017 & 26 \\
\hline Seyhan Nehri doğal çevreyi gözlemlemek ve öğrenmek için ortam sunar. & 0.464 & 19 & -0.475 & 30 \\
\hline $\begin{array}{l}\text { Seyhan Nehri bilim, sanat ve edebiyat alanında yeni fikirler ve eserler geliştirilmesi için } \\
\text { yaratıcılığ } 1 \text { harekete geçirir. }\end{array}$ & 0.331 & 20 & 0.000 & 24 \\
\hline Seyhan Nehri toplumla iletişim kurmak için ortam sağlar. & 0.313 & 21 & 0.541 & 15 \\
\hline Seyhan Nehri'nden avlanma yoluyla besin sağlanır & 0.299 & 22 & 0.344 & 20 \\
\hline Dinlenme ve spor faaliyetleri Seyhan Nehri olmadan da yapılabilir. & 0.228 & 23 & 1.308 & 5 \\
\hline $\begin{array}{l}\text { Seyhan Nehri yaşanılan toplumun ve çevrenin bir parçası olma duygusunun (aidiyet } \\
\text { duygusu) gelişmesine katkı sağlar. }\end{array}$ & 0.225 & 24 & 0.972 & 10 \\
\hline Doğa ve çevre sevgisi Seyhan Nehri olmadan da gelişebilir. & -0.031 & 25 & 1.767 & 3 \\
\hline Seyhan Nehri atıkların ortamdan uzaklaşmasını ve bertarafını sağlar. & -0.189 & 26 & -1.847 & 48 \\
\hline İçme suyu Seyhan Nehri'nden başka bir çok kaynaktan sağlanabilir. & -0.352 & 27 & -0.515 & 33 \\
\hline Doğa ve çevre Seyhan Nehri olmadan da gözlemlenip öğrenilebilir. & -0.378 & 28 & 0.427 & 18 \\
\hline Atıkların bertarafında Seyhan Nehri'nin etkisi yoktur. & -0.524 & 29 & 0.951 & 11 \\
\hline Doğadaki besin göngüsü Seyhan Nehri olmadan da gerçekleşebilir. & -0.530 & 30 & 1.264 & 7 \\
\hline Yaban hayatı türleri Seyhan Nehri olmadan da yaşam ortamı bulabilir. & -0.572 & 31 & -0.081 & 28 \\
\hline Çevreye yönelik aidiyet duygusu Seyhan Nehri ile ilgili olmayan bir konudur. & -0.588 & 32 & 0.438 & 17 \\
\hline Havadaki kirletici maddelerin temizlenmesinde Seyhan Nehri etkisizdir. & -0.714 & 33 & -0.695 & 36 \\
\hline Yaratıcılığın gelişmesinde Seyhan Nehri rol oynamaz. & -0.719 & 34 & -0.504 & 32 \\
\hline Seyhan Nehri'nin göz ve ruh üzerindeki dinlendirici etkisi diğer manzaralarla aynıdır. & -0.826 & 35 & -1.191 & 42 \\
\hline Yüzey akışlarının düzenlenmesi Seyhan Nehri ile ilgili olmayan bir süreçtir. & -0.866 & 36 & 0.000 & 23 \\
\hline Ekosistemin bütünlüğü Seyhan Nehri olmadan da sağlanabilir. & -0.971 & 37 & -1.060 & 41 \\
\hline Doğal su dengesi Seyhan Nehri olmadan da sağlanabilir. & -0.999 & 38 & -1.539 & 45 \\
\hline Seyhan Nehri sosyal etkileşim için uygun olmayan ortamlar sunar. & -1.038 & 39 & 1.835 & 1 \\
\hline Seyhan Nehri'nin besin sağlanmasına katkısı azdır. & -1.131 & 40 & 1.025 & 9 \\
\hline Çevre Seyhan Nehri olmadan da güzel görünebilir. & -1.145 & 41 & -1.022 & 39 \\
\hline İklimin iyileşmesinde Seyhan Nehri önemli rol oynamaz. & -1.195 & 42 & 1.398 & 4 \\
\hline Seyhan Nehri turistlerin ilgisini çekmez. & -1.237 & 43 & 1.046 & 8 \\
\hline Tarımsal sulama Seyhan Nehri olmadan da yapılabilir. & -1.309 & 44 & 0.000 & 25 \\
\hline Seyhan Nehri'nin yerleşim cazibesi diğer yerler ile aynıdır. & -1.328 & 45 & -1.374 & 44 \\
\hline Çevrenin karakteri üzerinde Seyhan Nehri rol oynamaz. & -1.380 & 46 & -0.950 & 38 \\
\hline Seyhan Nehri enerji üretiminde etkin rol oynamaz. & -1.677 & 47 & -1.291 & 43 \\
\hline Biyoçeşitlilik Seyhan Nehri ile ilgili olmayan bir konudur. & -1.696 & 48 & -0.898 & 37 \\
\hline
\end{tabular}


Faktörler bazında ifadelerin aldığı Z değerleri, katılımcı grupların ayrı veya ortak görüş geliştirdikleri durumlar üzerine de bilgi vermektedir. Örneğin; "Seyhan Nehri tarımsal sulama için kaynak sağlar.” ifadesi 1 nolu faktörde "1.”, 2 nolu faktörde ise "47." sırada yer alarak birbirine zıt görünüm sergilemiştir. Yine, "Seyhan Nehri içme suyu için kaynak sağlar." ifadesi 1 nolu faktörde önemli ölçüde kabul görerek "6." sırada yer bulmuş, 2 nolu faktörü meydana getiren katılımcılar ise aynı ifadeyi dizginin "Katılmıyorum" kısmına daha yakın konumlandırarak "46." sırada yer almasını sağlamışlardır. Faktörler arasında geliştirilen ortak görüş için "Çevre Seyhan Nehri olmadan da güzel görünebilir." ifadesi örnek olarak verilebilmektedir. Bu ifade her iki faktörde de kabul görmeyerek alt sıralarda yer almış, "Seyhan Nehri doğanın ve ekosistemin bütünlügünü destekler." ifadesine ise her iki faktörde olumlu yaklaşılarak üst sıralarda yer verilmiştir.

\section{Tartışma ve Sonuç}

Bu çalışmada, bir konu hakkında büyük veya küçük tüm grupların görüşlerinin ortaya konulabilmesine ve böylece araştırmacıların bütün bakış açıları üzerine bilgi sahibi olmasına imkan tanıyan Q metodoloji yardımıyla (Pike vd., 2015) Seyhan Nehri’nden sağlanan ekosistem hizmetlerine yönelik bakış açılarının belirlenmesi amaçlanmıştır. Analiz sonuçları, konuya yönelik iki farklı faktör söz konusu olmakla birlikte, yaş veya cinsiyet farkı gözetmeksizin katılımcıların büyük oranda belirli bir bakış açısı etrafinda toplandığını göstermişstir. Katılımcıların çoğunluğunun yer aldığı 1 nolu faktörde üzerinde hemfikir olunan başlıca ifade "Seyhan Nehri tarımsal sulama için kaynak sağlar.” olmuştur. Bu sonuç, Türkiye ve bölge tarımı için büyük önem taşıyan Çukurova'yı besleyen Seyhan Nehri'nden sağlanan hayatî yararlara yönelik yüksek bir farkındalık söz konusu olduğunu işaret etmektedir. "Seyhan Nehri yerleşim için cazibe oluşturur." ifadesi katılımcılar tarafından en çok kabul gören ekosistem hizmetleri arasında ikinci sırada yer almıştır. Bu durum, Adana kentsel yerleşiminin ortaya çıkmasında ve gelişmesinde önemli rol oynayan Seyhan Nehri'nin (Çanak, 2015) yapılaşma üzerindeki etkilerine vurgu yapılması bakımından önem taşımaktadır. Katılımcılar, Seyhan Nehri'nin doğal sistem içerisindeki yeri ve önemine "Seyhan Nehri doğanın ve ekosistemin bütünlüğünü destekler." ifadesine üçüncü sırada yer vererek atıfta bulunmuşlardır. Yine benzer şekilde, Seyhan Nehri’nin içme suyu ve enerji sağlanmasına yönelik katkıları, su döngüsünü ve iklimi iyileştirme üzerindeki etkileri, çevreye kimlik ve görsel kalite kazandırması gibi yararları 1 nolu faktörde üst sıralarda yer bulmuştur.

2 nolu faktörde üzerinde en çok birleşilen ifadeler incelendiğinde, katılımcıların ekosistemlerden sağlanan hizmetler bağlamında Seyhan Nehri’ne önemli anlamlar yüklemedikleri anlaşılmaktadır. Örneğin bu faktörde; iklimin iyileşmesi üzerinde Seyhan Nehri'nin önemli rol oynamadığı, Seyhan Nehri'nin sosyal etkileşim için uygun olmayan ortamlar sunması, doğa ve çevre sevgisinin Seyhan Nehri olmadan da gelişebileceği gibi ifadelere üst sıralarda yer verilmiştir. Bu durum, araştırılan konuya yönelik farkındalıkların, önceliklerin ve farklı seslerin ortaya konulabilmesinde Q metodolojinin sağladığı avantajları göstermesi bakımından önem taşımaktadır. Q metodoloji uygulamasında olumlu ve olumsuz ifadelere bir arada yer verilmesi konu hakkındaki görüşlerin geniş bir bakış açısıyla yansıtılmasına, ifadeler arasında denge ve temsiliyetin sağlanmasına imkan tanımaktadır. Bir Q metodoloji hazırlık sürecinde yalnızca olumlu ifadeler elde edilmişse, farklı görüşlerin temsiliyetine olanak sağlayabilmek için her ifadenin bir de karşıt anlamlısının tesis edilmesine ihtiyaç bulunmaktadır (Amin, 2000). Nitekim Seyhan Nehri için gerçekleştirilen bu çalışmada da ilk etapta yalnızca olumlu ifadeler elde edilmiş, bu nedenle sonrasında her ifadenin bir de olumsuzunun hazırlanması yoluna gidilmiştir.

Ekosistem hizmetlerine yönelik bakış açılarının incelenmesi, toplumun beklentileri nezdinde ve karar vericilere yön gösterecek nitelikte o ekosistemin veya kaynağın nasıl yönetilmesi gerektiğini işaret eden bir işlemdir. Kaynak yönetimine yönelik bir ekosistem hizmetleri yaklaşımı, insanların ekosistemleri nasıl etkilediğinin ötesine geçerek insanların ekosistemlere nasıl bağlı olduğunu, ekosistemlerden nasıl yararlandığını ve bundan nasıl etkilendiğini içermektedir. Kaynak yönetimi yalnızca doğal ekosistemlerin korunması veya muhafazası ile ilgili değil, daha çok insanlar ve bağlı oldukları kaynaklar arasındaki dinamiği tanımlamakla ilgili bir süreçtir (Loomis ve Paterson, 2014). Bu yaklaşımlar ile hareket edildiğinde, insanların ekosistemlerden sağlanan yararlara yönelik bakış açılarının irdelenmesi önemli bir ihtiyaç olarak belirmektedir.

$\mathrm{Bu}$ çalışma kapsamında elde edilen verilerden ve yapılan değerlendirmelerden yola çıkılarak araştırmacılara, plancılara ve yöneticilere yönelik bir dizi öneriler geliştirebilmek mümkündür. Seyhan Nehri’ne yönelik olarak ileride gerçekleştirilecek benzer araştırmalar açısından bakıldığında, bu araştırma ile elde edilen bakış açılarının detaylandırılması düşünülebilir. Çünkü Q metodoloji yaklaşımı konuya yönelik çözümler sunmamakta, paydaşların görüşlerinin çok kapsamlı bir resmini vererek konu ile ilgili tüm bakış açılarının duyulmasını sağlamaktadır (Pike vd., 2015). Diğer bir deyişle Q metodoloji araştırılan konuyla ilgili sorunları derinlemesine analiz etmemekte, sorunları, politika seçeneklerini ve tercih edilen önlemleri işaret ederek daha fazla araştırma için temel oluşturmaktadır. Örneğin Seyhan Nehri için gerçekleştirilen bu çalışma göz önüne alındığında, olumsuz görüşlerin ortaya çıkma nedenlerini veya bu olumsuzlukları gidermeye yönelik olarak alınabilecek 
önlemlerin belirlenmesini hedefleyen yeni çalışmaların yapılabilmesi mümkündür. Diğer taraftan, Seyhan Nehri'nden sağlanan ekosistem hizmetlerine yönelik olarak geliştirilen olumlu görüşlerin desteklenmesini ve nehrin bu özelliklerinin korunarak geliştirilmesini sağlayacak çalışmaların yapılması önerilmektedir.

Q metodoloji ile yapılacak çalışmaların görüşleri ve öncelikleri belirlemede, araştırmalara yön vermede, plancıların ve yöneticilerin çalışmalarını daha verimli hale getirmelerine 1şık tutmada önemli bir araç olduğu bu çalışma ile ortaya konulmaya çalışılmıştır. Q metodoloji ile gerçekleştirilecek çalışmaların ekosistem hizmetlerine yönelik bakış açılarını belirleme ile sınırlı kalmayarak çevre sorunları, kentsel ve kırsal peyzaj planlama, doğa koruma gibi konularda etkin şekilde kullanılması gerektiği bu çalışma kapsamında geliştirilebilecek diğer öneriler arasında yer almaktadır.

\section{Kaynaklar}

1. Anonim (2020). Adana 5 Ocak Gazetesi, https://www.5ocakgazetesi.com (08.10.2020)

2. Anonim (2021). Seyhan Nehri, https://tr.wikipedia.org/wiki/Seyhan_Nehri (12.01.2021)

3. Amin, Z. (2000). Q Methodology - A journey into the subjectivity of human mind. Singapore Medical Journal, 41(8), 410-414.

4. Brown, S. R. (1993). A primer on Q methodology. Operant Subjectivity, 16(3/4), 91-138.

5. Buchel, S., Frantzeskaki, N. (2015). Citizens' voice: A case study about perceived ecosystem services by urban park users in Rotterdam, the Netherlands. Ecosystem Services, 12, 169-177.

6. Chee, Y. E. (2004). An ecological perspective on the valuation of ecosystem services. Biological Conservation, 120 ,549-565.

7. Cheng, X., Van Damme, S., Li, L., Uyttenhove, P. (2019). Evaluation of cultural ecosystem services: A review of methods. Ecosystem Services, 37, 100925.

8. Covich, A., Ewel, K. C., Hall, C. A. S., Giller, P. G., Merritt, D. M., Goedkoop, W. (2004). Ecosystem services provided by freshwater benthos. In Sustaining Biodiversity and Ecosystem Services in Soils and Sediments Ed. Wall, D. H., Island Press, pp. 45-72.

9. Christie, M., Fazey, I., Cooper, R., Hyde, T., Kenter, J. O. (2012). An evaluation of monetary and nonmonetary techniques for assessing the importance of biodiversity and ecosystem services to people in countries with developing economies. Ecological Economics, 83,67-78.

10. Cross, R. M. (2005). Exploring attitudes: the case for Q methodology. Health Education Research, 20(2),206-213.

11. Curt, B. (1994). Textuality and tectonics: troubling social and psychological science. Open University Press, Buckingham.

12. Çanak, E. (2015). Cumhuriyet Döneminde Adana'da (Seyhan) Meydana Gelen Seller ve Alınan Önlemler (1930-1956). Manisa Celal Bayar Üniversitesi Sosyal Bilimler Dergisi, 13(1), 296 - 341.

13. Çiftcioğlu, G. C. (2018). Revealing major terrestrial- and marine species-based provisioning ecosystem services provided by the socio-ecological production landscapes and seascapes of Lefke Region in North Cyprus. Environment, Development and Sustainability, 20(1),197-221.

14. Çiftcioğlu, G. C., Ebedi, S., Abak, K. (2019). Evaluation of the relationship between ornamental plants based ecosystem services and human wellbeing: A case study from Lefke Region of North Cyprus. Ecological Indicators, 102,278-288.

15. Davies, B. B., Hodge, I. D. (2007). Exploring environmental perspectives in lowland agriculture: A Q methodology study in East Anglia, UK. Ecological Economics, 61, 323-333.

16. De Groot, R., Fisher, B., Christie, M., Aronson, J., Braat, L., Gowdy, J., Haines-Young, R., Maltyby, E., Neuville, A., Polasky, S., Portela, R., Ring, I. (2010). Integrating the ecological and economic dimensions in biodiversity and ecosystem service valuation. In The Economics of Ecosystems and Biodiversity: Ecological and Economic Foundations, Ed. G.K. Kadekodi, Earthscan, London and Washington.

17. Demir, F., Kul, M. (2011). Modern Bir Araştırma Yöntemi Q Metodu. Adalet Yayınevi, Ankara.

18. Gret-Regamey, A., Siren, E., Hanna Brunner, S., Weibel, B. (2017). Review of decision support tools to operationalize the ecosystem servicesconcept. Ecosystem Services, 26,306-315.

19. Hermans, F., Kok, K., Beers, P. J., Veldkamp, T. (2011). Assessing sustainability perspectives in rural innovation projects using Q-Methodology. Sociologia Ruralis, 52, 70-90.

20. Jacobsen, J. K. S. (2007). Use of landscape perception methods in tourism studies: A review of photo based research approaches. Tourism Geography, 9(3), 234-253.

21. Karasu, M., Peker, M. (2019). Q Yöntemi: Tarihi, Kuramı ve Uygulaması. Türk Psikoloji Yazıları, 22(43), 28-39. 
22. Kerr, G. N., Swaffield, S. R. (2012). Identifying cultural service values of a small river in the agricultural landscape of Canterbury, New Zealand, using combined methods. Society and Natural Resources, 25, $1330-1339$.

23. Loomis, D. K., Paterson, S. K. (2014). The human dimensions of coastal ecosystem services: Managing for social values. Ecological Indicators, 44,6-10.

24. Martinez, M. L., Intralawan, A., Vázquez, G., Pérez-Maqueo, O., Sutton, P., Landgrave, R. (2007). The coasts of our world: Ecological, economic and social importance. Ecological Economics, 63,254-272.

25. MEA (Millenium Ecosystem Assessment) (2005). Ecosystems and Human Well-Being: Policy Responses, Vol 3. Eds. Chopra, K., Leemans, R., Kumar, P., Simons, H. Island Press, 607 p.

26. Oteros-Rozas, E., Martın-Lopez, B., Gonzalez, J. A., Plieninger, T., Lopez, C. A., Montes, C. (2014). Socio-cultural valuation of ecosystem services in a transhumance social-ecological network. Regional Environmental Change, 14,1269-1289.

27. Pike, K., Wright, P., Wink, B., Fletcher, S. (2015). The assessment of cultural ecosystem services in the marine environment using Q methodology, Journal of Coastal Conservation, 19, 667-675.

28. Sala, R., Oltra, C., Gonçalves, L. (2015). Attitudes towards urban air pollution: a Q methodology study / Actitudes frente a la contaminación atmosférica urbana: un estudio basado en el método Q. Psyecology, 6(3), 359-385.

29. Scholte, S. S. K., van Teeffelen, A. J. A., Verburg, P. H. (2015). Integrating socio-cultural perspectives into ecosystem service valuation: A review of concepts and methods. Ecological Economics, 114,67-78.

30. Shuib, S. B., Hashim, H., Nasir, N. A. M. (2017). Q methodology for assessing urban park values among stakeholders. Sustainable Development and Planning VIII, Vol.: 210, 469 - 480.

31. Simpson, S., Brown, G., Peterson, A., Johnstone, R. (2016). Stakeholder perspectives for coastal ecosystem services and influences on value integration in policy. Ocean and Coastal Management, 126, 921.

32. Stainton Rogers, R., (1995). Q methodology. In: J.A. Smith, R. Harre, L. Van Langenhove, (Eds.), Rethinking methods in psychology. Sage, London.

33. Steelman, T. A., Maguire, L. A. (1999). Understanding participant perspectives: Q-Methodology in national forest management. Journal of Policy Analysis and Management, 18(3), 361-388.

34. Stephenson, W. (1935). Technique of factor analysis. Nature, 136, 297.

35. Swaffield, S. R., Fairweather, J. R. (1996). Investigation of attitudes towards the effects of land use change using image editing and Q sort method. Landscape and Urban Planning, 35, 213-230.

36. Watts, S., Stenner, P. (2005). Doing Q methodology: theory, method and interpretation. Qualitative Research in Psychology, 2(1), 67-91.

37. Webler, T., Danielson, S., Tuler, S. (2009). Using Q method to reveal social perspectives in environmental research. Greenfield MA: Social and Environmental Research Institute. https://www.serius. org/pubs/Qprimer.pdf (08.10.2020)

38. Van Wilgen, B. W., Cowling, R. M., Burgers, C. J. (1996). Valuation of ecosystem services: A case study from South African fynbos ecosystems. BioScience, 46(3),184-189.

39. Yıldırım, İ. (2017). Eğitimin oyunlaştırılmasına ilişkin öğrenci algıları: Bir Q metodu analizi. Eğgitim ve Bilim, 42(191), 235-246.

40. Zivojinovic, I., Wolfslehner, B. (2015). Perceptions of urban forestry stakeholders about climate change adaptation - A Q-method application in Serbia. Urban Forestry and Urban Greening, 14, 1079-1087. 